\title{
Effects of test expectancy (recall vs. recognition) on children's recall and recognition
}

\author{
JAMES W. HALL, ROSEMARIE MISKIEWICZ, and CHERYL GAY MURRAY \\ Northwestern University, Evanston, Illinois 60201
}

\begin{abstract}
Following practice lists for recall and recognition, a third list was given for which half the third- and sixth-grade children expected a recall test and half a recognition test. All children then were given a recall test followed by a recognition test. Recall by sixth graders was better when a recall rather than a recognition test was expected. Test expectancy did not affect the recall of third graders, nor did it apparently affect recognition at either grade level. Selfreports indicate greater preexperimental understanding of task difficulty differences at Grade 6. At Grade 6, but not at Grade 3, reports of rehearsal of items in blocks (rather than single-item repetition) were more frequent when a recall test was expected and reports of image production were more frequent when a recognition test was expected.
\end{abstract}

The experiment reported here addresses questions concerning the nature and development of memory encoding strategies for free recall vs. recognition of familiar, relatively unrelated nouns. In design it is similar to studies with adults concerning differential encoding for recall vs. recognition (Hall, Grossman, \& Elwood, 1976). In those experiments recall was enhanced when a recall test was expected, whereas recognition did not appear to be altered by the test expectancy manipulation. Self-report data suggested that the critical encoding difference between expectancy conditions was primarily quantitative. That is, the deliberate rehearsal activities reported were similar but with more of such rehearsal reported by those preparing for a recall test. In other words, college students employed a simple but useful strategy of studying harder for a recall test than for a recognition test.

The main concerns in the present experiment were (1) the course of development of differential strategies for recognition and recall, (2) the nature of any strategic differences, and (3) the development of awareness of the differing demands of recall and recognition. Interest in such questions is not new. Kreutzer, Leonard, and Flavell (1975) obtained judgments of the relative difficulty of recognition vs. recall of pictures by children in Grades k, 1, 3, and 5. Most children at each of these grade levels indicated that the recognition would be easier. However, Kreutzer et al. were skeptical of the validity of these data because of possible misunderstandings, especially by the younger children. And even when

This research was supported by Research Grant 5RO1 HD 07311-02 from the National Institute of Child Health and Human Development. Thanks are due the school officials, teachers, and students of Haven Middle School and Martin Luther King Jr. Laboratory School in Evanston whose cooperation made this research possible. Requests for reprints should be addressed to James W. Hall, School of Education, Northwestern University, Evanston, Illinois 60201. children display the relevant metamemorial understanding, they may not capitalize fully on that knowledge to enhance actual performance (Kelly, Kofsky, Scholnick, Travers, \& Johnson, 1976, Experiment 2). Thus, one might expect some lag between the age at which children first display the understanding of the more stringent demands of recall and the age at which they display differing rehearsal behaviors for recall and recognition.

In an unpublished study of the effects of recall vs. recognition test expectancy on recall by school children in Grades 6, 7, 9, and 11, our results essentially replicated those obtained by Hall et al. (1976) with college students. Since we obtained no Age by Test Expectancy interaction, we were led to search for the origin of the test expectancy effect with somewhat younger children. Accordingly, the present experiment examined the effects of test expectancy with children in Grades 3 and 6. In addition, judgments of the relative difficulty of recall and recognition and interview data concerning rehearsal activities were obtained. Our expectations were that the effect of test expectancy would be greater at Grade 6 than at Grade 3, that more sixth graders than third graders would possess preexperimental knowledge of the greater difficulty of the recall task, and that at Grade 6 the children expecting a recall test would report more elaborate rehearsal activities than would those expecting a recognition test.

\section{METHOD}

\section{Subjects}

The subjects were 48 third-grade and 48 sixth-grade children. The children were randomly selected from their respective classes and, although varying widely in socioeconomic status (SES), as a group were somewhat above average in achievement and SES.

\section{Design and Procedure}

All of the children received a free recall and a recognition 
practice list, with task order counterbalanced, followed by the critical list on which test expectation was varied. Following a free recall test on the critical list, a recognition test on those items also was given. The practice study lists each contained 16 items and the critical study list contained 18 items. Each study list was typed on a sheet of paper in a single column, and two random orders of each list were used. The recognition tests consisted of the study words and an equal number of distractors randomly ordered and displayed in two columns on a single sheet of paper. The various lists were constructed by using the most readable and familiar (in the experimenter's judgment) of the various items used in Experiment 3 of the Hall et al. (1976) studies. All third graders received a 90 -sec study period for each list; sixth graders received 72 -sec study periods. All free recall periods were $2 \mathrm{~min}$ in length.

Within each of the above conditions, half the subjects were tested individually and half in groups of three. The purpose of the individual testing was to facilitate obtaining the task difficulty judgments and self-report data to be described shortly. The study period procedures were identical for the group and individual subjects, while test procedures differed somewhat. For recall the individual subjects gave their responses orally, whereas the group subjects wrote theirs on sheets of lined paper. The group subjects were told that spelling was not an important consideration, and the experimenter checked their sheets following each session to clarify any ambiguities. For individual subjects the recognition test sheets were displayed and the experimenter read each word aloud, with the child indicating orally whether the word was "old" or "new." For group subjects the recognition test lists were given to the children and they were asked to circle the old items. For all children it was emphasized (repeatedly, if necessary) that they were to continue their study until told to stop, and on the free recall tests the children were encouraged to keep trying if they seemed to give up during the period.

Two task difficulty judgments were obtained from those children seen individually. The first was obtained following the child's completion of the first practice test (either recall or recognition) and the experimenter's instructions concerning the second practice task. At that point, the child had just directly experienced one of the tasks and had received a verbal description of the second. After the second practice task, the child was asked again to judge the relative difficulty of the two tasks.

Following the final recognition test, each of the individual children was again shown the final study list and was asked to describe his study methods, with frequent encouragement and requests for clarification and demonstration. Then the experimenter described and demonstrated, in turn, five study strategies based on an earlier study with college students (Hall et al., 1976. Experiment 1). The first three of these were item repetition strategies involving (1) repeatedly reading through the list, (2) repeating each word several times before moving to the next, or (3) repeating blocks of words that appeared close together on the list. The fourth was an associative strategy of skipping around in the list to find words that "sort of go together." The fifth was an imagery strategy of "picturing the things in your head that the words made you think of." The children were asked to rate the frequency of their use of these strategies and, to be certain of their understanding, to demonstrate their use of each strategy.

\section{RESULTS AND DISCUSSION}

A 2 by 2 by 2 by 2 by 2 ANOVA with one repeated measure was applied to the data. The variables were grade (sixth vs. third), expectancy (recall vs. recognition), list (practice vs. critical), administration (group vs. individual), and order (of the practice lists). Test was
Table 1

Mean Recall

\begin{tabular}{|c|c|c|c|c|c|}
\hline \multirow[b]{2}{*}{ List } & \multirow[b]{2}{*}{$\begin{array}{l}\text { Critical Test } \\
\text { Expectancy }\end{array}$} & \multicolumn{2}{|c|}{ Grade 3} & \multicolumn{2}{|c|}{ Grade 6} \\
\hline & & $\begin{array}{c}\text { Individ- } \\
\text { ual }\end{array}$ & Group & $\begin{array}{l}\text { Individ- } \\
\text { ual }\end{array}$ & Group \\
\hline Practice & $\begin{array}{l}\text { Recall } \\
\text { Recognition }\end{array}$ & $\begin{array}{l}5.08 \\
4.50\end{array}$ & $\begin{array}{l}6.17 \\
6.42\end{array}$ & $\begin{array}{l}8.33 \\
9.17\end{array}$ & $\begin{array}{l}8.35 \\
7.08\end{array}$ \\
\hline Critical & $\begin{array}{l}\text { Recall } \\
\text { Recognition }\end{array}$ & $\begin{array}{l}3.83 \\
3.58\end{array}$ & $\begin{array}{l}6.25 \\
5.42\end{array}$ & $\begin{array}{l}8.25 \\
7.17\end{array}$ & $\begin{array}{l}9.25 \\
4.75\end{array}$ \\
\hline
\end{tabular}

the within-subjects variable. The data are summarized in Table 1.

Considering first the main effects, recall increased with grade level $[F(1,80)=36.51, \mathrm{p}<.01]$ and was greater when a recall test was expected $[F(1,80)=4.45$, $\mathrm{p}<.05]$ and for the practice vs. the critical test $[F(1,96)=13.16, p<.01]$. Among the significant interactions, the one of greatest interest was the predicted three-way interaction of Grade by Expectancy by List $[F(1,80)=6.31, p<.05]$. That interaction, depicted in Figure 1, reflects a greater effect of test expectancy on recall for the older children, precisely what would be anticipated. In fact, there was virtually no such effect at Grade 3. The Expectancy by List interaction also was significant $[F(1,80)=11.21, p<.01]$. The significant interactions of Test by Order $[\mathrm{F}(1,80)=4.58, \mathrm{p}<.05]$ and of Grade by List by Order $[F(1,80)=12.40$, $\mathrm{p}<.01]$ evidently reflect the tendency for greater proactive interference for the third graders when the critical list was immediately preceded by the recognition practice task, with the reverse trend at Grade 6. No plausible explanation can be offered for that effect,

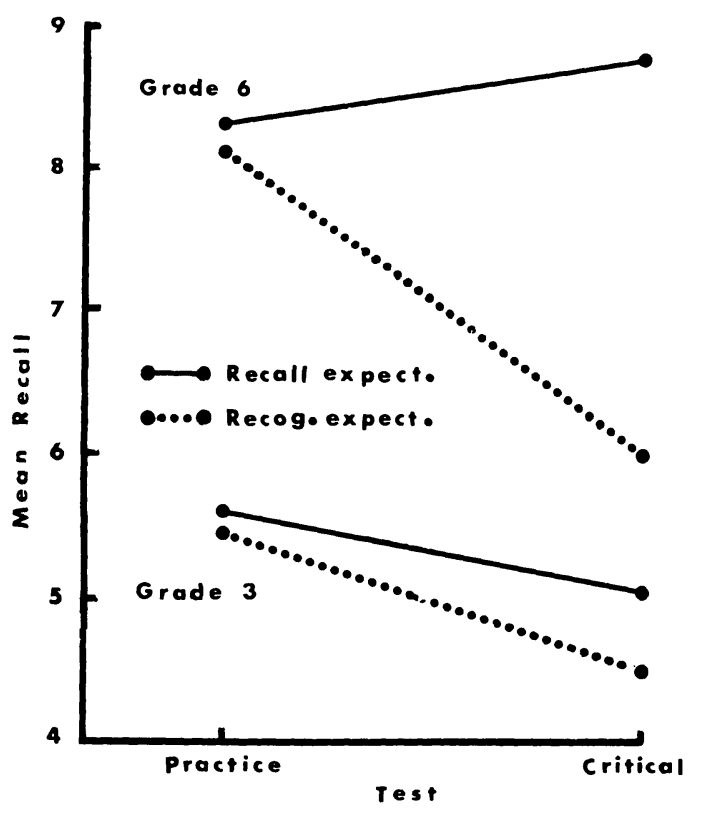

Figure 1. Recall of third and sixth graders as a function of test expectancy. 
nor for the significant Grade by Administration interaction $[F(1,80)=9.71, p<.01]$, wherein the performance of the younger children was enhanced by group administration with no comparable difference at Grade 6 .

Interpretation of the final recognition data is complicated by the fact that the final recognition task was preceded by recall, giving, in effect, another study presentation for the items recalled. Thus, whenever recognition effects paralleled the recall effects, as was true for grade level and for group vs. individual administration, interpretation is ambiguous and statistical analyses unwarranted. One recognition finding is of interest, though: the absence of any hint of the test expectancy effect found for free recall. At Grade 6, where recall was markedly greater for the recall expectancy condition, mean hit and false alarm rates, respectively, on the critical test were 14.71 and 1.71 for the recall expectancy condition and 15.25 and 1.54 for the recognition expectancy condition, a difference that was negligible and in the opposite direction from that of recall. It appears that the encoding differences induced by the test expectancy manipulation were neutral with respect to recognition performance, although that conclusion must be tentative until the effect can be evaluated in the absence of potential contamination from a prior recall test.

The expected age difference in judgments of relative task difficulty was found. On initial judgments (made before the children had taken both types of tests), only $33 \%$ of the younger children judged the recall task as more difficult, whereas $88 \%$ of the sixth graders did so. Following experience with both practice tests, children at both grade levels overwhelmingly judged the free recall task to be more difficult (88\% and $79 \%$, respectively). Thus, the absence of any substantial test expectancy effect on third-graders' recall cannot be attributed to an absence of awareness of the greater difficulty of the free recall task.

The self-report data concerning study strategies yielded several findings of interest. First, the most commonly reported strategy at both age levels was simply the continuous reading through the items in the order in which they appeared. Rehearsal (repetition) of items in blocks was reported by $54 \%$ of the sixth graders but by only $25 \%$ of the third graders, a marginally significant difference $\left(\chi^{2}=3.14, \mathrm{df}=1, .10>\mathrm{p}>.05\right)$. Some effort to search the list for associatively related items was reported by $50 \%$ of the sixth graders but by only $12 \%$ of the third graders, $\left[\chi^{2}=6.21\right.$, df $=1$, $\mathrm{p}<.05]$. At the sixth-grade level, 9 of the 12 children expecting free recall reported rehearsal of items in blocks, while only 4 of 12 in the recognition expectancy condition did so, a marginally significant difference $\left[\chi^{2}=2.68, \mathrm{df}=1, \mathrm{p} \approx .10\right]$. Also at Grade 6 , nine children expecting recognition, but only two expecting recall, reported attempts to produce visual images of objects denoted by the study words, $\left[\chi^{2}=6.04, \mathrm{df}=1\right.$, $\mathrm{p}<.05]$. No other expectancy or age differences approached significance.

Our data suggest that the effect of test expectation on recall of relatively unrelated items emerges between about 7 and 11 years of age. By Grade 6 most of the children were aware from previous experience (presumably) that the demands of recall are more stringent (ordinarily) than are those of recognition, and at least some of them adjusted their behavior accordingly. And, in contrast to the earlier studies with college students (Hall et al., 1976), the self-report data suggest qualitative differences in processing. Most third graders, on the other hand, were not aware of the task difficulty difference until they had been administered both of the practice tasks during the experimental session. However, nearly all of the third graders did reach that conclusion once given both practice lists, and still there was no discernible recall superiority for those expecting recall at that age level. Nor did the study strategy interview reports of those children suggest any rehearsal differences between the expectancy conditions. Apparently, some longer time in possession of such information is required before the child spontaneously alters study behavior based on that information. Such a developmental gap between knowing and acting has been reported for other phenomena related to memory (see, e.g., Hagen, Jongeward, \& Kail, 1975, pp. 90-91 for a related discussion).

Subsequent to the completion of our experiment, Naus, Ornstein, and Kreshtool (1977) reported data on rehearsal, recall, and recognition differences as a function of recall vs. recognition test expectancy for third- and sixth-grade children. In that experiment rehearsal was overt, study items were presented successively and aurally, the children were given information regarding alternative rehearsal activities, an interval of about $24 \mathrm{~h}$ occurred between study and test, and the children were higher in SES and about 2 months older on the average than those in our study. One or a combination of those differences very likely accounts for the fact that Naus et al. did not find an interaction between test expectancy and age either in rehearsal activity or in recall performance. Except for that disparity, the results of the two studies are generally similar. At Grade 6, the Naus et al. children were more likely to rehearse items in blocks and exhibited greater recall when a recall rather than a recognition test was expected, and recognition performance was unaffected by test expectancy. Thus, the Naus et al. data require no alteration of our own conclusions except to suggest that the age at which test expectancy effects first are found is likely to vary somewhat with the characteristics of the children studied and with procedural variations. 


\section{REFERENCES}

Hagen, J. W. Jongeward, R. H., JR., \& KaIl, R. V., JR. Cognitive perspectives on the development of memory. In $\mathrm{H}$. W. Reese (Ed.). Advances in child development and behavior (Vol. 10). New York: Academic Press, 1975.

Hall, J. W., Grossman, L. R., \& Elwood, K. D. Differences in encoding for free recall vs. recognition. Memory \& Cognition, 1976, 4, 507-513.

Kelly, M. Kofsky, E., Scholnick, E. K., Travers, S. H., \& Johnson. J. W. RElations among mémory, memory appraisal, and memory strategies. Child Development, 1976, 45, 648-659.
Kreutzer, M. S., Leonard, C., \& Flavell, J. H. An interview study of children's knowled ge about memory. Monographs of the Society for Research in Child Development. 1975. 40(1. Serial No. 159).

Naus, M. J., Ornstein, P. A.. \& Kreshtool, K. Developmental differences in recall and recognition: The relationship between rehearsal and memory as test expectation changes. Journal of Experimental Child Psychology, 1977. 23. 252-265.

(Received for publication August 1, 1977.) 